\title{
Growth Modelling of Listeria monocytogenes in Korean Pork Bulgogi Stored at Isothermal Conditions
}

\author{
Na-Kyoung Lee ${ }^{1}$, Sin Hye Ahn ${ }^{1}$, Joo-Yeon Lee ${ }^{2}$, and Hyun-Dong Paik ${ }^{1,3, *}$ \\ ${ }^{1}$ Department of Food Science and Biotechnology of Animal Resources, Konkuk University, Seoul 143-701, Korea \\ ${ }^{2}$ Korea Livestock Products HACCP Management Institute, Anyang 430-731, Korea \\ ${ }^{3}$ Bio/Molecular Informatics Center, Konkuk University, Seoul 143-701, Korea
}

\begin{abstract}
The purpose of this study was to develop predictive models for the growth of Listeria monocytogenes in pork Bulgogi at various storage temperatures. A two-strain mixture of L. monocytogenes (ATCC 15313 and isolated from pork Bulgogi) was inoculated on pork Bulgogi at $3 \mathrm{Log}$ CFU/g. L. monocytogenes strains were enumerated using general plating method on Listeria selective medium. The inoculated samples were stored at 5,15 , and $25^{\circ} \mathrm{C}$ for primary models. Primary models were developed using the Baranyi model equations, and the maximum specific growth rate was shown to be dependent on storage temperature. A secondary model of growth rate as a function of storage temperature was also developed. As the storage temperature increased, the lag time (LT) values decreased dramatically and the specific growth rate of L. monocytogenes increased. The mathematically predicted growth parameters were evaluated based on the modified bias factor $\left(B_{f}\right)$, accuracy factor $\left(A_{f}\right)$, root mean square error $(R M S E)$, coefficient of determination $\left(\mathrm{R}^{2}\right)$, and relative errors (RE). These values indicated that the developed models were reliably able to predict the growth of L. monocytogenes in pork Bulgogi. Hence, the predictive models may be used to assess microbiological hygiene in the meat supply chain as a function of storage temperature.
\end{abstract}

Key words: predictive model, Listeria monocytogenes, Baranyi model, pork Bulgogi

\section{Introduction}

Pork Bulgogi is a Korean traditional food made from thin slices of pork, usually picnic ham, shank ham, or marinated ham (Shin et al., 2011). When the meat is marinated with spices (containing soy sauce, onion, ginger, garlic, sesame oil, and other seasonings), pathogenic bacteria may contaminate the meat and subsequently be propagated via cut or whole meat that is intended for further processing into meat products. Recently pork $\mathrm{Bul}$ gogi has been sold as a ready-to-cook (RTC) product in markets. RTC foods, including pork Bulgogi, are typically displayed uncovered and hence exposed to contamination by bacterial pathogens. Thus, several food-borne disease outbreaks have been associated with the consumption of contaminated RTC foods (Jo et al., 2003). However, the safety of these products during distribution

\footnotetext{
*Corresponding author: Hyun-Dong Paik, Department of Food Science and Biotechnology of Animal Resources, Konkuk University, Seoul 143-701, Korea. Tel: +82-2-2049-6011, Fax: +822-455-3082, E-mail: hdpaik@konkuk.ac.kr
}

and sale is frequently not monitored (Björkroth, 2005; Nguyen-The and Carlin, 1994). The number of cases of food-borne disease caused by the consumption of contaminated RTC foods is increasing. In 2012, 266 cases of food poisoning were reported in Korea, and 6,058 cases of food poisoning have been reported to date (KFDA, 2013). This has necessitated the development of predictive models to maintain food quality and avoid undesired pathogenic bacteria in food.

Predictive models are mathematical expressions that describe the growth, survival, and inactivation of foodborne microorganisms. Such models have been used extensively to predict the safety of foods under various environmental conditions, including temperature, $\mathrm{pH}$, and composition. Since the growth and survival of microorganisms are greatly affected by the conditions for model development, it is very important to consider the characteristics of the food in the model (Gibson et al., 1988; Kang et al., 2010).

Listeria monocytogenes is the main pathogen of concern in refrigerated meat products such as RTC meats (Sofos, 2008). This is because such products can be re- 
contaminated during slicing and packaging. The microbiological analysis of $L$. monocytogenes in marinated broiler legs has been reported (Aarnislao et al., 2008). In healthy adults, the doses of $L$. monocytogenes required to cause listeriosis have been reported to vary from $10^{5}$ to $10^{9} \mathrm{CFU} / \mathrm{g}$ (Dalton et al., 1997; Miettinen et al., 1999). However, in high-risk groups, infectious doses ranging from $<10$ and $10^{4} \mathrm{CFU} / \mathrm{g}$ have been reported (Berrang et al., 1988; Ericsson et al., 1997). In Europe, the acceptable level of L. monocytogenes in foods is defined as $<10^{2}$ $\mathrm{CFU} / \mathrm{g}$ at the consumption (Anonymous, 2005). The aim of this study was to develop predictive models for $L$. monocytogenes, considering variables of temperature and storage time in RTC pork Bulgogi.

\section{Materials and Methods}

\section{Bacterial strains}

Two strains of L. monocytogenes (ATCC 15313 and isolated from pork Bulgogi) were used in previous study (Ahn et al., 2012). The strains were maintained in Tryptic Soy Broth (TSB, Difco Laboratories, USA) containing $20 \%$ glycerol at $-80^{\circ} \mathrm{C}$. The stock cultures were thawed at room temperature, and $100 \mu \mathrm{L}$ of culture was then inoculated into $10 \mathrm{~mL}$ of TSB and incubated at $35^{\circ} \mathrm{C}$ for $24 \mathrm{~h}$ to reach at concentration of $>8 \mathrm{Log} \mathrm{CFU} / \mathrm{mL}$.

\section{Microbiological analysis, $\mathrm{pH}$, and salt concentra- tion of samples}

Pork Bulgogi samples were purchased from a retail outlet in Seoul. Since L. monocytogenes was not detected in these samples, $10 \mathrm{~g}$ portions were cut without vegetables, aseptically transferred them into sterile stomacher bag (VWR, USA) and added $90 \mathrm{~mL}$ of $0.1 \%$ peptone water (Difco Laboratories, USA). Total plate counts were determined on Plate Count Agar (PCA, Difco Laboratories) for $48 \mathrm{~h}$ at $35^{\circ} \mathrm{C}$, and coliform and Escherichia coli were identified on Petrifilms ${ }^{\mathrm{TM}}$ Plates $\left(3 \mathrm{M}^{\mathrm{TM}}\right.$, USA) for $24 \mathrm{~h}$ at $37^{\circ} \mathrm{C}$.

The $\mathrm{pH}$ was measured with a $\mathrm{pH}$ meter (inoLab, Germany), and the salt concentration was determined by a saltmeter (Takemura Electric Works Ltd., Japan). Three replicates of each sample were tested.

\section{Inoculation and enumeration}

A $100 \mu \mathrm{L}$ of mixed strains of L. monocytogenes was inoculated onto each surface of pork Bulgogi and blended. The initial cell counts were adjusted to $3 \mathrm{Log}$ CFU/ $\mathrm{mL}$. The inoculated samples were stored at 5, 15, and 25
${ }^{\circ} \mathrm{C}$ to develop the primary growth models. These samples were then diluted with $90 \mathrm{~mL}$ of $0.1 \%$ peptone water, plated onto Oxford Agar with Modified Oxford Antimicrobic Supplement (MOX, Difco Laboratories, USA), and incubated at $35^{\circ} \mathrm{C}$ for $48 \mathrm{~h}$.

\section{Primary modelling}

The Baranyi model was used for primary modelling based on the obtained data (Baranyi and Roberts, 1994; Baranyi et al., 1995). The growth parameters in the primary model were including time variable (A), bacterial cell density $(\mathrm{y})$, maximum specific growth rate $\left(\mu_{\max }\right)$, and lag time (LT) were determined at each temperature with the Baranyi model using MicroFit version 1.0 software (Advanced and Hygienic Food Manufacturing LINK Programme, UK). The reparameterized model is described by Equations [1], [2], and [3].

$$
\begin{aligned}
& y(t)=y_{0}+\mu_{\max } A(t)-\ln \left(1+\frac{e^{\mu_{\max } A(t)-1}}{e^{\left(y_{\max }-y_{0}\right)}}\right) \\
& A(t)=t+\frac{1}{\mu_{\max }} \ln \left[\frac{e^{-\mu_{\max } t}+q_{0}}{1+q_{0}}\right] \\
& L T=\frac{\ln \left(1+\frac{1}{q_{0}}\right)}{\mu_{\max }}
\end{aligned}
$$

\section{Secondary modelling}

To describe the effects of temperature $\left(5,15\right.$, and $\left.25^{\circ} \mathrm{C}\right)$ on growth of bacteria, lag time (LT), and maximum specific growth rate (SGR), the polynormial model equation was chosen, based on the parameter of primary models. The model is described by Equations [4] and [5]. $a, b$, and $c$ are constant, and $\mathrm{T}$ is temperature.

$$
\begin{aligned}
& \operatorname{Ln}(L T)=a+b T+c T^{2} \\
& \operatorname{Ln}(S G R)=a+b T+c T^{2}
\end{aligned}
$$

\section{Evaluation of predictive models}

To evaluate the model performance of the predicted models, coefficient of determination $\left(\mathrm{R}^{2}\right)$, modified bias factor $\left(B_{f}\right)$, accuracy factor $\left(A_{f}\right)$, and root mean square error (RMSE) was used in Equations [6], [7], and [8] (Abou-Zeid et al., 2009; Ross, 1996).

$$
B_{f}=10\left\{\frac{\Sigma \log \left(\frac{\text { pred }}{o b s}\right)}{n}\right\}
$$




$$
\begin{aligned}
& A_{f}=10 \\
& \left\{\frac{\sum \mid \log \left(\frac{\text { pred }}{\text { obs }}\right)}{n}\right\} \\
& R M S E=\sqrt{\frac{\sum(\text { obs }- \text { pred })^{2}}{n}}
\end{aligned}
$$

The obs, pred, and $n$ parameters indicate observed value, predicted value, and repetition number of observed data, respectively. Perfect agreement between predictions and observations leads to bias and accuracy factor equal to 1.0. If $A_{f}$ value higher than 1, that indicated predicted values are larger than observed values. RMSE is effectively the average difference between the model and the data points.

The relative errors (RE) of individual prediction cases was performed as an additional validation (DelignetteMuller et al., 1995) :

$$
\begin{aligned}
& R E \text { for } L T=\frac{(\text { pred }-o b s)}{\text { pred }} \\
& R E \text { for } S G R=\frac{(\text { obs }- \text { pred })}{\text { pred }}
\end{aligned}
$$

The acceptable prediction zone of prediction cases were represented as RE values from -0.3 to 0.15 .

\section{Statistical analysis}

Experiments were repeated twice and the results were analyzed using the Statistical Analysis System (SAS version 9.1, SAS Institute Inc., USA). The data were expressed as mean \pm standard deviation (SD).

\section{Results and Discussion}

\section{Pork Bulgogi's compositional properties}

The compositional properties of pork Bulgogi were investigated. The total plate counts and coliform count for pork Bulgogi was 5.3 Log CFU/g and 3.5 Log CFU/g, respectively, while $E$. coli was not detected (Table 1). The $\mathrm{pH}$ and salt concentration was 5.79 and $1.52 \%$, respec-

Table 1. Properties of pork Bulgogi

\begin{tabular}{cc}
\hline \hline Properties & Values (Mean \pm SD) \\
\hline Total plate counts (Log CFU/g) & $5.32 \pm 0.03$ \\
Coliform (Log CFU/g) & $3.54 \pm 0.47$ \\
E. coli $(\log$ CFU/g) & $\mathrm{ND}^{1)}$ \\
pH & $5.79 \pm 0.02$ \\
Salt concentrate (\%) & $1.52 \pm 0.12$ \\
\hline
\end{tabular}

\footnotetext{
${ }^{1)}$ Not detected.
}

tively. A previous report on Bulgogi sauce indicated that the $\mathrm{pH}$ and salt concentration was 5.41 and $2.01 \%$, respectively, which is similar to our results (Nam et al., 2010). L. monocytogenes has known as can be survive in $\mathrm{pH}$ 4.4-9.4 and 10\% NaCl (ICMSF, 1996). The compositional properties of pork Bulgogi indicate that it has favorable conditions for the growth of L. monocytogenes.

\section{Development of predictive models for L. monocyto- genes}

The growth of L. monocytogenes inoculated onto pork Bulgogi is shown for different storage temperatures (Fig. $1)$. The initial bacterial count of $L$. monocytogenes was 3.2-3.4 Log CFU/g. Table 2 shows the growth parameters obtained from the Baranyi model. The maximum cell counts $\left(y_{\max }\right)$ of L. monocytogenes at storage temperatures $\left(5,15\right.$, and $\left.25^{\circ} \mathrm{C}\right)$ were 3.5-4.0 Log $\mathrm{CFU} / \mathrm{g}$ within $96 \mathrm{~h}$ and not exceeded 4.1 Log CFU/g. After 24 h, L. monocytogenes was not detected in pork Bulgogi stored at 15 and $25^{\circ} \mathrm{C}$. This might be ascribed to be possible changes in the storage conditions. For instance, L. monocytogenes was known to be affected by alkaline $\mathrm{pH}$ or microbial competition with bacteria such as lactic acid bacteria (Eom et al., 2009; Vasseur et al., 1999).

The growth curves showed that the storage temperature was decreased, the generation time and LT of microorganisms are increased and the growth is slowed (Fig. 2). The maximum specific growth rate would increase gradually with values of $0.07 \mathrm{Log} \mathrm{CFU} / \mathrm{g} \cdot \mathrm{h}, 0.30 \mathrm{Log} \mathrm{CFU} /$ $\mathrm{g} \cdot \mathrm{h}$, and $0.90 \mathrm{Log} \mathrm{CFU} / \mathrm{g} \cdot \mathrm{h}$, and that LT would decrease gradually with values of $38.7 \mathrm{~h}, 8.07 \mathrm{~h}$, and $4.7 \mathrm{~h}$ at stor-

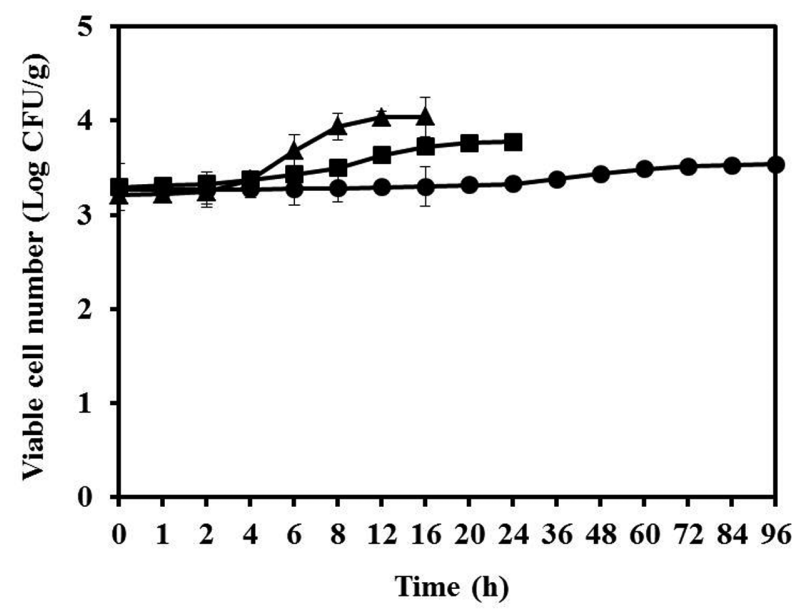

Fig. 1. The growth of $L$. monocytogenes in pork Bulgogi at various storage temperature $\left(\bullet: 5^{\circ} \mathrm{C}, \square: 15^{\circ} \mathrm{C}, \triangle\right.$ : $25^{\circ} \mathrm{C}$ ). 
Table 2. Growth parameters of $L$. monocytogenes in pork Bulgogi at various storage temperatures

\begin{tabular}{ccccc}
\hline \hline \multirow{2}{*}{ Temperature $\left({ }^{\circ} \mathrm{C}\right)$} & \multicolumn{4}{c}{ Growth parameters (Mean \pm SD) } \\
\cline { 2 - 5 } & $y_{0}{ }^{1)}$ & $y_{\max }{ }^{2)}$ & $\mu_{\max }{ }^{3)}$ & $\mathrm{LT}^{4)}$ \\
\hline 5 & $3.25 \pm 0.04$ & $3.54 \pm 0.09$ & $0.07 \pm 0.09$ & $38.7 \pm 15.38$ \\
15 & $3.27 \pm 0.04$ & $3.78 \pm 0.06$ & $0.30 \pm 0.15$ & $8.07 \pm 1.86$ \\
25 & $3.20 \pm 0.04$ & $4.04 \pm 0.04$ & $0.90 \pm 0.25$ & $4.70 \pm 0.52$ \\
\hline
\end{tabular}

${ }^{1)}$ Initial cell count (Log CFU/g).

${ }^{2)}$ Maximum cell count ( $\left.\mathrm{Log} \mathrm{CFU} / \mathrm{g}\right)$.

${ }^{3)}$ Maximum specific growth rate (Log CFU/g $\left.\cdot h\right)$.

${ }^{4)}$ Lag time (h).
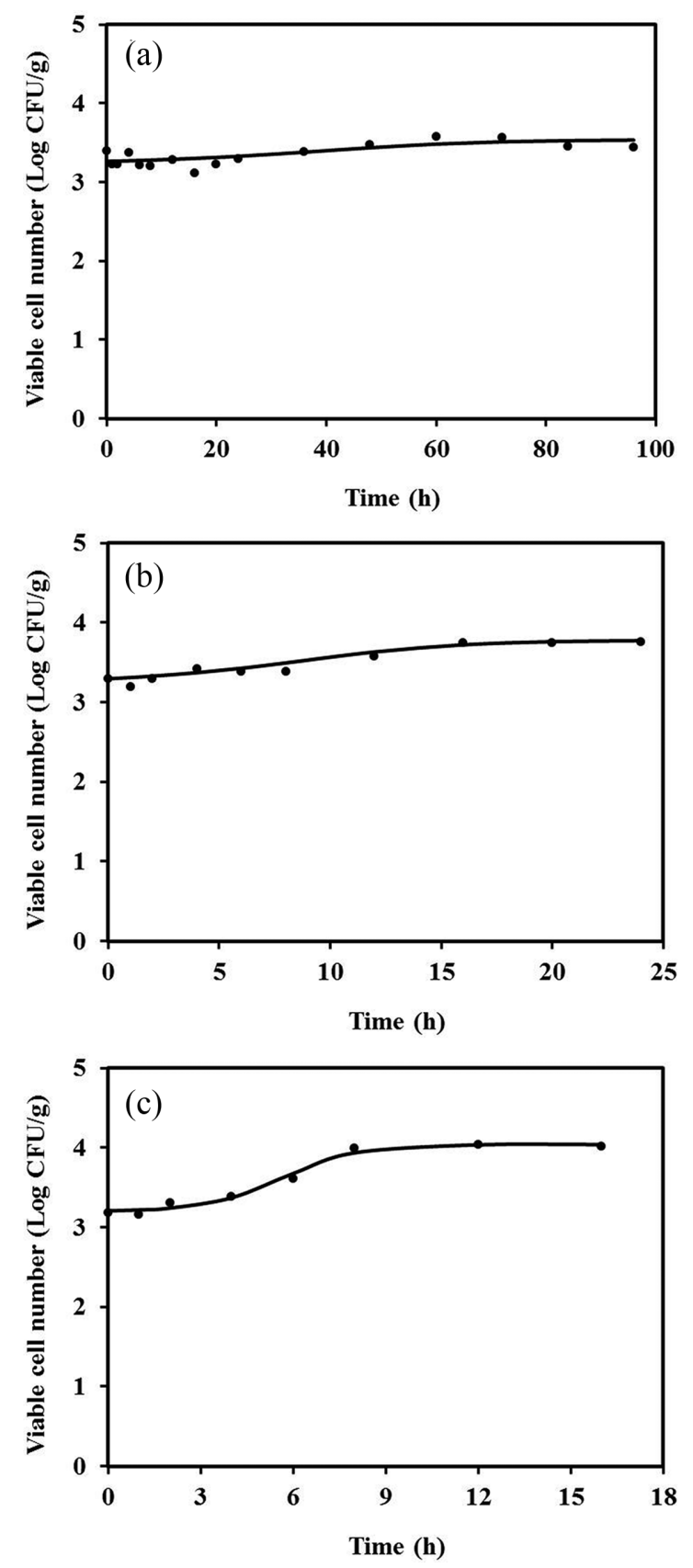

Fig. 2. Primary models at (A) $5^{\circ} \mathrm{C}$, (B) $15^{\circ} \mathrm{C}$, and (C) $25^{\circ} \mathrm{C}$ obtained from the predicted model (-) and experimental data ( $\bullet$ ). age temperatures of 5,15 , and $25^{\circ} \mathrm{C}$, respectively (Table 2). Obtained real results were fit well to predictive line. These results indicate that the growth of microorganisms was influenced by storage temperature. It has been reported that temperature is one of the most important environmental parameters affecting microbial growth and spoilage in meat or meat products (Thomas and Matthews, 2005).

A secondary model was developed to describe how the primary model parameters, including SGR and LT, were affected by temperature (Fig. 3). As storage temperature increased, SGR increased and LT was shortened, according to a secondary model for maximum SGR and LT (Equation (4) and (5)). Other studies have shown that the
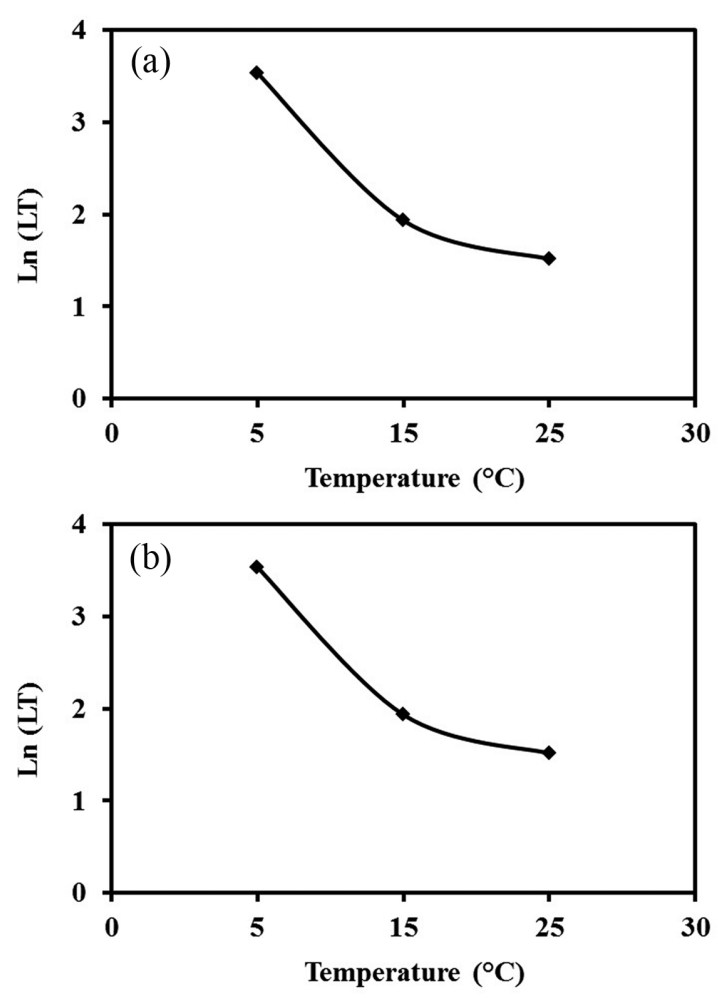

Fig. 3. Secondary models for the effect of storage temperature on growth parameters (a) SGR, specific growth rate and (b) LT, lag time. 
Table 3. Evaluation of primary models for $L$. monocytogenes in pork Bulgogi

\begin{tabular}{ccccc}
\hline \hline Temperature $\left({ }^{\circ} \mathrm{C}\right)$ & $\mathrm{R}^{2, \mathrm{I})}$ & $R M S E^{2)}$ & $B_{f}^{3)}$ & $A_{f}^{4)}$ \\
\hline 5 & 0.602 & 0.08 & 1.005 & 1.021 \\
15 & 0.862 & 0.06 & 1.01 & 1.014 \\
25 & 0.960 & 0.05 & 1.002 & 1.011 \\
\hline
\end{tabular}

${ }^{1)}$ Coefficient of determination.

${ }^{2)}$ Root mean square error.

${ }^{3)}$ Bias factor.

${ }^{4)}$ Accuracy factor.

most significant factor for bacterial growth is storage temperature (Gospavic et al., 2008; Hong et al., 2005).

\section{Evaluation of predictive models}

The chemical composition of food changes over time, which can influence the growth of spoilage or pathogenic bacteria. Therefore, a gap between predicted data and observed data can exist. Predicted data are generally based on growth in an aqueous phase, such as broth, and typically indicate faster growth rates than those observed in solid phase, such as, for instance, sausages (Koutsoumanis and Nychas, 2000; Wilson et al., 2002). To solve this problem, we have developed models that show a more accurate prediction of bacterial growth in pork Bulgogi.

To evaluate the developed predictive models, we used the following indexes used for model performance of predicted and observed data: $R^{2}, R M S E, B_{f}$, and $A_{f}$. Table 3 shows that the data obtained from the samples stored at 5 , 15 , and $25^{\circ} \mathrm{C}$ fit well into the Baranyi model. Although the $\mathrm{R}^{2}$ values are somewhat low, that is likely because it is not recommended to judge model performance with non-linear regression (Ross, 1996), and the growth of $L$. monocytogenes was insufficient for comparison with previous predictive models. Thus, $B_{f}$ and $A_{f}$ are the recommended indices to judge model performance (Baranyi et al., 1995). $B_{f}$ is used to consider whether predictions are in the fail-safe direction or not. Acceptable values for a $B_{f}$ range from 0.700 to 1.150 . By contrast, acceptable values of $A_{f}$ depend on the number of model variables considered (Oscar, 2005). The $B_{f}$ values for temperatures of 5, 15 , and $25^{\circ} \mathrm{C}$ were $1.005,1.01$, and 1.002 , respectively, and the $A_{f}$ values were $1.021,1.014$, and 1.011 , respec- tively. The $B_{f}$ values showed that the predictive bacterial counts exceeded the observed data by approximately. Therefore, the values of the $R^{2}, R M S E, B_{f}$, and $A_{f}$ statistics indicate that the primary model could provide accurate predictions of the growth data and reliably describe the bacterial growth curves in our samples.

The $B_{f}$ and $A_{f}$ values were $0.957,1.045$ in the LT model and 1.097, 1.097 in the SGR model (Table 4). $B_{f}$ and $A_{f}$ values in both LT and SGR models were close to 1, which indicated a good fit between the observations and the predictions. The RMSE value in the LT and SGR model was 0.12 and 0.09 , respectively. In addition, RE values for LT and SCR was 0.02 to 0.14 and -0.14 to -0.02 . These values was acceptable prediction zone, -0.3 to 0.15 (Oscar, 2005). Therefore, these results demonstrate that the predictions made in this study are reliable. Therefore, the models may be applied to ensure the safety of meat and to establish standards to avoid microbial contamination of meat. In addition, this study could be provide an evaluation index for the safety of products in cases of temperature abuse or process deviations within hazard analysis and critical control points (HACCP) system.

\section{Acknowledgements}

This work was supported by the Priority Research Centers Program through the National Research Foundation of Korea (NRF) funded by the Ministry of Education, Science, and Technology (2009-0093824).

\section{References}

1. Aarnislao, K., Vihavainen, E., Rantala, L., Maijala, R., Suihko, M. L., Hielm, S., Tuominen, P., Ranta, J., and Raaska, L. (2008) Use of results of microbiological analyses for riskbased control of Listeria monocytogenes in marinated broiler legs. Int. J. Food Microbiol. 121, 275-284.

2. Abou-Zeid, K. A., Oscar, T. P., Schwarz, J. G., Hashem, F. M., Whiting, R. C., and Yoon, K. S. (2009) Development and validation of a predictive model for Listeria monocytogenes scott $\mathrm{A}$ as a function of temperature, $\mathrm{pH}$ and commercial mixture of potassium lactate and sodium diacetate. J. Microbiol. Biotechnol. 19, 718-726.

Table 4. Evaluation of secondary models for specific growth rate (SGR) and lag time (LT) of $L$. monocytogenes in pork Bulgogi

\begin{tabular}{cccc}
\hline \hline Ln $\left(\mathrm{LT}\right.$ or SGR) $=a+b \times \mathrm{T}+c \times \mathrm{T}^{2}$ & RMSE $^{\text {I) }}$ & $B_{f}^{2)}$ & $A_{f}^{3)}$ \\
\hline $\operatorname{Ln}(\mathrm{SGR})=-3.7757+0.2041 \times \mathrm{T}-0.0023 \times \mathrm{T}^{2}$ & 0.09 & 1.097 & 1.097 \\
$\operatorname{Ln}(\mathrm{LT})=4.7749-0.2779 \times \mathrm{T}+0.0059 \times \mathrm{T}^{2}$ & 0.12 & 0.957 & 1.045 \\
\hline
\end{tabular}

\footnotetext{
${ }^{1)}$ Root mean square error.

${ }^{2)}$ Bias factor.

${ }^{3)}$ Accuracy factor.
} 
3. Ahn, S. H., Lee, Y. J., Lee, J. Y., and Paik, H. D. (2012) Microbiological investigation of ready-to-cook pork bulgogi on Korean markets. Korean J. Food Sci. An. 32, 441-447.

4. Anonymous (2005) Commission Regulation (EC) No. 2073/ 2005 of 15 November 2005 on microbiological criteria for foodstuffs. Official Journal of the European Union, L338, $1 \mathrm{e} 26$.

5. Baranyi, J. and Roberts, T. A. (1994) A dynamic approach to predicting bacterial growth in food. Int. J. Food Microbiol. 23, 277-294.

6. Baranyi, J., Robinson, T. P., Kaloti, A., and Mackey, B. M. (1995) Predicting growth of Brochothrix thermosphacta at changing temperature. Int. J. Food Microbiol. 27, 61-75.

7. Berrang, M. E., Frank, J. F., and Brackett, R. E. (1988) Behaviour of Listeria monocytogenes in chocolate milk and ice cream mix made from post-expiration date skim milk. J. Food Prot. 51, 823.

8. Björkroth, J. (2005) Microbiological ecology of marinated meat products. Meat Sci. 70, 477-480.

9. Dalton, G. B., Austin, C. C., Sobel, J., Hayes, P. S., Bibb, W. F., Graves, L., Swaminathan, B., Proctor, M. E., and Griffin, P. M. (1997) An outbreak of gastroenteritis and fever due to Listeria monocytogenes in milk. New Engl. J. Med. 336, 100105.

10. Delignette-Muller, M. L., Rosso, L., Flandrois, J. P. (1995) Accuracy of microbial growth predictions with square root and polynormial models. Int. J. Food Microbiol. 27, 139-146.

11. Eom, S., Jung, Y., and Yoon, K. (2009) Effect of sanitizer stress response on the growth kinetics of Listeria monocytogenes on imitation crabmeat and in broth as a function of temperature. J. Food Safety 29, 564-574.

12. Ericsson, H., Eklöw, A., Danielsson-Tham, M. L., Loncerevic, S., Mentzing, L. O., Persson, I., Unnerstad, H., and Tham, W. (1997) An outbreak of listeriosis suspected to have been caused by rainbow trout. J. Clin. Microbiol. 35, 2904-2907.

13. Gibson, A. M., Bratchell, N., and Roberts, T. A. (1988) Predicting microbial growth: growth responses of Salmonella in a laboratory medium as affected by $\mathrm{pH}$ sodium chloride, and storage temperature. Int. J. Food Microbiol. 6, 155-178.

14. Gospavic, R., Kreyenschmidt, J., Bruckner, S., Popov, V., and Haque, N. (2008) Mathematical modeling for predicting the growth of Pseudomonas spp. in poultry under variable temperature conditions. Int. J. Food Microbiol. 127, 290-297.

15. Hong, C. H., Sim, W. C., Chun, S. J., Kim, Y. S., Oh, D. H., Ha, S. D., Choi, W. S., and Bahk, G. J. (2005) Predictive growth model for native isolated Listeria monocytogenes on raw pork as a function of temperature and time. Korean $J$. Food Sci. Technol. 37, 850-855.

16. ICMSF (International Commission on the Microbiological Specification of Foods) (1996). Choice of sampling plan and criteria for Listeria monocytogenes. Int. J. Food Microbiol. 22, 89-96.
17. Jo, C., Han, C. H., Chung, K. H., and Byun, M. W. (2003) Gamma irradiation of ready-to-cook bulgogi improves safety and extends shelf-life without compromising organoleptic qualities. Nutr. Food 8, 191-195.

18. Kang, K. A., Kim, Y. W., and Yoon, K. S. (2010) Development of predictive growth models for Staphylococcus aureus and Bacillus cereus on various food matrices consisting of ready-to-eat (RTE) foods. Korean J. Food Sci. An. 30, 730738.

19. KFDA (2013) The report of foodborne illness in Korea, Available from http://e-stat.kfda.go.kr/ Accessed April.

20. Koutsoumanis, K. and Nychas, G. J. E. (2000) Application of a systematic experimental procedure to develop a microbial model for rapid fish shelf life predictions. Int. J. Food Microbiol. 60, 171-184.

21. Miettinen, M. K., Siitonen, A., Heiskanen, P., Haajanen, H., Brörkroth, K. J., and Korkeala, H. J. (1999) Molecular epidemiology of an outbreak of febrile gastroenteritis caused by Listeria monocytogenes in cold-smoked rainbow trout. J. Clin. Microbiol. 37, 2358-2360.

22. Nam, J. S., Choi, S. K., and Kim, D. S. (2010) Quality and sensory characteristics of bulgogi sauce with various amount of omija extract juice. Korean J. Culinary Res. 16, 247-259.

23. Nguyen-The, C. and Carlin, F. (1994) The microbiology of minimally processed fresh fruits and vegetables. Crit. Rev. Food Sci. Nutr. 34, 370-401.

24. Oscar, T. P. (2005) Validation of lag time and growth rate models for Salmonella Typhimurium: acceptable prediction zone method. J. Food Sci. 70, M129-M137.

25. Ross, T. (1996) Indices for performance evaluation of predictive models in food microbiology. J. Appl. Bacteriol. 81, 501508.

26. Sofos, J. N. (2008) Challenges to meat safety in the 21 st century. Meat Sci. 78, 3-13.

27. Shin, M. H., Park, J. G., Kim, C. J., and Lee, J. W. (2011) Development ready-to-eat bulgogi sauce with no change of sensory properties after high-dose irradiation. Korean J. Food Sci. An. 31, 366-371.

28. Thomas, J. M. and Matthews, K. R. (2005) Food microbiology: an introduction. ASM Press, Washington DC, pp. 247250 .

29. Vasseur, C., Baverel, L., Hébraud, M., and Labadie, J. (1999) Effects of osmotic, alkaline, acid or thermal stresses on the growth and inhibition of Listeria monocytogenes. J. Appl. Microbiol. 86, 469-476.

30. Wilson, P. D. G., Brocklehurst, T. F., Arino, S., Thuault, D., Jakobsen, M., Lange, M., Farkas, J., Wimpenny, J. W., and Van Impe, J. F. (2002) Modelling microbial growth in structured foods: towards a unified approach. Int. J. Food Microbiol. 73, 275-289.

(Received 2014.12.10/Revised 2014.12.24/Accepted 2014.12.24) 